\title{
Study of heterogeneities in steels and determination of soluble and total aluminium and titanium concentration by laser ablation inductively coupled plasma mass spectrometry
}

\author{
Aurora G. Coedo ${ }^{\mathrm{a}, *}$, Teresa Dorado ${ }^{\mathrm{a}}$, Isabel Padilla ${ }^{\mathrm{a}}$, Juan C. Fariñas ${ }^{\mathrm{b}}$

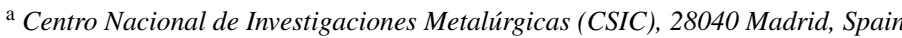 \\ b Instituto de Cerámica y Vidrio (CSIC), Campus de Cantoblanco, 28049 Madrid, Spain \\ Received 25 May 2006; received in revised form 6 October 2006; accepted 19 October 2006 \\ Available online 13 November 2006
}

\begin{abstract}
A methodology for bulk analysis of $\mathrm{Al}$ and $\mathrm{Ti}$ and for determination of soluble and total $\mathrm{Al}$ and $\mathrm{Ti}$ concentration in steel samples by laser ablation inductively coupled plasma mass spectrometry was developed. The spatial distribution (both at surface and within the sample) of the insoluble fraction of $\mathrm{Al}$ and Ti was also qualitatively estimated. Certified reference materials (CRMs) SS-451 to 460 (carbon steel) and 064-1 $(\mathrm{Nb} / \mathrm{Ti}$ interstitial free steel), from BAS, and JK 2D (carbon steel) and JK 37 (highly alloyed steel), from SIMR, were studied. It was demonstrated that the insoluble fraction of $\mathrm{Al}$ and $\mathrm{Ti}$ is heterogeneously distributed. A series of nine glass samples (fused beads) with fixed Fe content and different $\mathrm{Al}$ and Ti contents was prepared by melting appropriate amounts of $\mathrm{Fe}_{2} \mathrm{O}_{3}, \mathrm{Al}_{2} \mathrm{O}_{3}$ and $\mathrm{TiO}_{2}$ with a lithium tetraborate-sodium carbonate mixture. Quantitative determinations were performed by using calibration graphs obtained from the synthetic fused beads, with ${ }^{57} \mathrm{Fe}$ as internal standard; line scan laser sampling mode was used, focusing the laser beam at the sample surface. The optimized laser operating parameters were: laser pulse energy of $1.5 \mathrm{~mJ}$, pulse repetition rate of $5 \mathrm{~Hz}$, scanning speed of $5 \mu \mathrm{m} \mathrm{s}^{-1}$ and preablation time of $20 \mathrm{~s}$. The concentrations obtained for bulk analysis of CRM samples corresponded with the certified values within the experimental uncertainty. An acceptable concordance between certified and found values was attained for the determination of soluble and total Al and Ti in CRM 064-1 sample.
\end{abstract}

(C) 2006 Elsevier B.V. All rights reserved.

Keywords: Laser ablation; Inductively coupled plasma mass spectrometry; $\mathrm{Al}$ and Ti inclusions; Steels

\section{Introduction}

The liquid steel contains a large amount of oxygen in he form of dissolved gases and iron oxides. The amount of oxygen that a steel can contain varies with the temperature and with the content of carbon and other elements. At high temperatures, the steel can dissolve a greater amount of oxygen, which tends to escape as the steel cools. The evolution of the gases and control of them during cooling affects the characteristics of the steel obtained, i.e. its internal cleanliness and uniformity, which significantly influences the finished product. All steels contain small amounts of non-metallic inclusions, primarily sulphides,

\footnotetext{
* Corresponding author.

E-mail addresses: coedo@cenim.csic.es (A.G. Coedo), jcfarinas@icv.csic.es (J.C. Fariñas).
}

silicates, and oxidized materials that are chiefly derived from the oxidizing reactions of the refining and casting processes. Deoxiders are added to control the gases given off, combining with the oxygen to form oxides that have a lower density, and float in the liquid steel in the ladle or in the ingot mould. The deoxidation process comprises three stages: dissolving of the deoxidizer, oxide formation and elimination of inclusions. Nevertheless deoxidation products cause the majority of indigenous inclusions, generated by the reaction between the dissolved oxygen and the added deoxidant. Aluminium and titanium provide effective deoxidation and inhibit austenitic grain growth [1]. The technical characteristics of the steel obtained depend on the method, place and deoxidiser used. Inclusions size can vary from sub to hundreds of micrometers where larger particles tend to be agglomerates of small particles rather than single individual precipitates. Steel cleanliness is a key issue that significantly influences the technical characteristics of the final product [2]. 
The usual procedure for the quantitative determination of soluble and total $\mathrm{Al}$ and Ti content consists in dissolving the sample in acid. The acid soluble fraction is considered as the soluble $\mathrm{Al}$ and $\mathrm{Ti}$ in the Fe matrix, though a very small part of the aluminium and titanium inclusions $\left(\mathrm{Al}_{2} \mathrm{O}_{3}\right.$ and $\mathrm{TiO}_{2}$, for example) can be partly dissolved in acids. The eventual insoluble residue is melted with alkaline fluxes. This procedure is time-consuming and labour intensive, and in addition increases the range of salts present in the solution and therefore the difficulties connected with subsequent determination by atomic spectrometry. Consequently, a simple and fast method able to identify the $\mathrm{Al}$ and $\mathrm{Ti}$ heterogeneities and to quantify soluble and total $\mathrm{Al}$ and $\mathrm{Ti}$ contents is required for product development, process control and quality assurance.

Laser ablation inductively coupled plasma mass spectrometry (LA-ICP-MS) is a rapid and sensitive analytical technique that is used in two major fields of applications: bulk analysis, with a low spatial resolution, and local analysis, with high spatial resolution [3-5]. To obtain information about the distribution of elements in heterogeneous solids, single point, line scan or rastering laser sampling modes can be performed. The depth profile distribution can be measured by focusing the laser beam at a steady position, while movable beam positions with respect to the sample surface allows the lateral distribution across the sample area to be profiled.

LA-ICP-MS was widely adopted in a variety of research areas of materials science [6]. It has been successfully applied to the direct analysis of steel composition and to the depth profile of different coatings on steel substrate. Yasuhara et al. [7] studied the optimum conditions for fixed Q pulse mode and Q-switched pulse mode, demonstrating that the Q-switched pulse mode was better for both non-metallic elements and elements with a high boiling-point. When determining non-metallic elements ( $\mathrm{Si}, \mathrm{P})$, in order to correct changes in background intensity, normalization with the Fe matrix and with the Ar ion is proposed. Ishibashi $[8,9]$ used a Q-switched Nd-YAG laser system for rapid analysis of steels using ICP-AES and ICP-MS. Calibration curves were prepared with standard steels, using $\mathrm{Fe}$ as internal standard. The precision in ICP-MS ranged from 5\% to $10 \%$. Also a semi-quantitative method was investigated, using the Fe signal as the base for signal compensation. Coedo et al. [10] used dried aerosol solutions for calibration in LA. Experimentally relative sensitivity factors (RSFs) were calculated and used to compensate for differences in sampling efficiency. Bleiner et al. [11] used ICP-TOFMS in combination with an excimer laser for depth profile analysis of Ti based single layers on different substrates. Plotnikov et al. [12] used a Nd:YAG $266 \mathrm{~nm}$ laser with ICP-QMS) to perform depth profile analysis of Tibased single layers deposited on steel and WC/Co substrates. Kanicky et al. [13] performed qualitative depth profiling of $3 \mu \mathrm{m}$ ZrTiN coatings using an homogenized beam from an ArF* $193 \mathrm{~nm}$ excimer laser. Coedo et al. [14] evaluated the feasibility of a Nd:YAG $266 \mathrm{~nm}$ laser for the depth profiling of steel substrate coated with copper single layers (Cu coating thicknesses ranging from 6 to $200 \mu \mathrm{m}$ ). One of the big advantages is the ability of the technique to provide information on spatial distribution in all three dimensions, dealing with inho- mogeneous samples. The changing transient signals produced can provide information about the presence of heterogeneities, although the time delay in the sample transport system (including the sample cell volume) is a limiting factor, causing signal mixing during the transportation of the ablated material, and preventing accurate identification of the exact origin of every signal. Plotnikov et al. [15] used the evolution of the parameters of single-shot response to reveal the true concentration profile of spatially inhomogeneous samples. Bleiner et al. [16] detail the principles and capabilities of the most common spatially resolved analytical techniques (XPS, AES, SIMS, SNMS, GDOES, GD-MS, SEM-EDX and LA-ICP-MS), comparing their spatial resolution and robust/powerful detection capability. Several of them (XPS, AES, SIMS, SNMS) offer nanometers depth resolution, but no more than qualitative trends. LA-ICP-MS, combining the strong detection power of the ICP-MS with the high spatial resolution of the focused laser beam $(10-100 \mu \mathrm{m}$ lateral, and $0.1-1 \mu \mathrm{m}$ depth), is presented as an ideal technique for quantitative spatially resolved analysis. Devos et al. [17] compared the advantages and drawbacks of LA-ICP-MS with electron probe microanalysis for spatially resolved trace analysis of early-medieval archaeological iron finds. Kang et al. [18] demonstrated the ability of the technique to provide elemental distribution information in micro spatial areas of dental tissues. Kindness et al. [19] developed a method for two-dimensional mapping of trace elements to identify the influence of metabolic zonation by the liver on trace element distribution. Becker et al. utilized LA-ICP-MS to produce images of element distribution in thin sections (20 $\mu \mathrm{m}$ thickness) of human [20] and rat [21] brain tissues. Karasev et al. [22] applied the technique to the analysis of total and insoluble contents of elements and inclusion composition in $\mathrm{Fe}-\mathrm{M}(\mathrm{M}=\mathrm{Al}, \mathrm{Ce}$ and $\mathrm{Ti})$ alloys. Izmer et al. [23] compared the use of line scan and single point modes to investigate elemental diffusion at the interface of NiCrAlYbased coatings on high-temperature alloys.

In many of the applications, quantification remains a challenge, and different approaches were proposed to prepare samples for calibration. Preparation of glass samples (fused beads) [24] or pellets [25] was performed to generate solid standards when matrix-matched certified reference materials are not available. Aeschliman et al. [26] used analyte signals from desolvated particles for a two-point calibration method, measuring online the transport of sample particulates from the ablation cell with a piezoelectric microbalance to provide signal normalization. Hoffmann et al. [27] pointed out that the precision and accuracy of the results are influenced by signal standardization, calibration standards and the mass-spectrometric measuring mode. Sanborn and Telmer [28] showed that line scan mode provided some advantages over spot analysis, obviating some complications such as changes in ablation yield and element fractionation that occur with increasing pit depth and Gaussian pit morphology.

The aim of the present work is to study the spatial distribution (both at surface and in depth) of the insoluble fraction of $\mathrm{Al}$ and Ti in steel samples by LA-ICP-MS, as well as to develop methodologies for bulk analysis of $\mathrm{Al}$ and $\mathrm{Ti}$ and for determination of soluble and total $\mathrm{Al}$ and $\mathrm{Ti}$. 


\section{Experimental}

\subsection{Instrumentation}

Experiments were performed with a commercially available quadrupled $(266 \mathrm{~nm})$ nanosecond Nd:YAG laser with Qswitch (LSX-100, CETAC Technologies, Omaha, Nebraska, USA) coupled to an ICP quadrupole mass spectrometer (ELAN 6000, Perkin-Elmer, Sciex, Ontario, Canada). The operating conditions of both the laser ablation and the ICP-MS instruments are listed in Table 1. Instrument conditions were optimized for best time-resolved data acquisition. A pure Fe sample was used for optimization. Fe signals were acquired and visually examined as a function of time. The monitoring of the signals in "real-time" allowed to change the operating parameters during the analysis and to select the best parameters setting in terms of sensitivity and stability. Laser pulse energy was measured with a laser power/energy meter (EM 400, Molectron Detector, Inc., USA). The depth and width of the craters and of the tracks were measured by optical microscopy, and their morphology was observed by scanning electron microscopy, SEM (DSM 400, Zeiss, Germany).

\subsection{Samples}

Certified reference materials (CRMs) SS-451 to 460 (carbon steel, residual series) and 064-1 ( $\mathrm{Nb} / \mathrm{Ti}$ interstitial free steel), from the Bureau of Analysed Samples (BAS), and JK 2D (carbon
Table 2

Certified values of $\mathrm{Al}$ and $\mathrm{Ti}$ in the CRM samples

\begin{tabular}{llc}
\hline Sample & $\mathrm{Al}(\%)$ & $\mathrm{Ti}(\%)$ \\
\hline SS-451 & - & $0.090 \pm 0.006$ \\
SS-452 & - & $0.020 \pm 0.002$ \\
SS-453 & - & $0.016 \pm 0.001$ \\
SS-454 & - & $0.0120 \pm 0.0005$ \\
SS-455 & - & $0.028 \pm 0.002$ \\
SS-456 & $0.008 \pm 0.001$ & - \\
SS-457 & $0.008 \pm 0.001$ & - \\
SS-458 & $0.140 \pm 0.005$ & - \\
SS-459 & $0.068 \pm 0.004$ & - \\
SS-460 & $0.028 \pm 0.002$ & - \\
JK 37 & $0.0084 \pm 0.0006$ & $0.0039 \pm 0.0006$ \\
JK 2D & $0.0249 \pm 0.0006$ & - \\
064-1 & $0.0330 \pm 0.0011^{\mathrm{a}}, 0.0302 \pm 0.0008^{\mathrm{b}}$ & $0.0189 \pm 0.0007$ \\
\hline
\end{tabular}

a Total content.

b Soluble content.

steel) and JK 37 (highly alloyed steel), from the Swedish Institute for Metals Research, were analyzed. SS-451 to 460, 064-1 and JK 2D samples have a similar Fe content of about 98-99\%, whereas JK 37 sample contains $26.7 \%$ of $\mathrm{Cr}, 30.8 \%$ of Ni, 3.5\% of Mo and a Fe concentration of about $40 \%$. Certified values for $\mathrm{Al}$ and Ti are listed in Table 2. Pure electrolytic iron BAM 0981 , from Bundesanstalt für Materialforschung und- prüfung, with $\mathrm{Al}$ and Ti contents lower than $1 \mathrm{ppm}$, was used as a blank. All of them are spectroscopic standard certified reference materials (38 $\mathrm{mm}$ diameter $\times 19 \mathrm{~mm}$ discs).

Table 1

LA-ICP-MS operating conditions

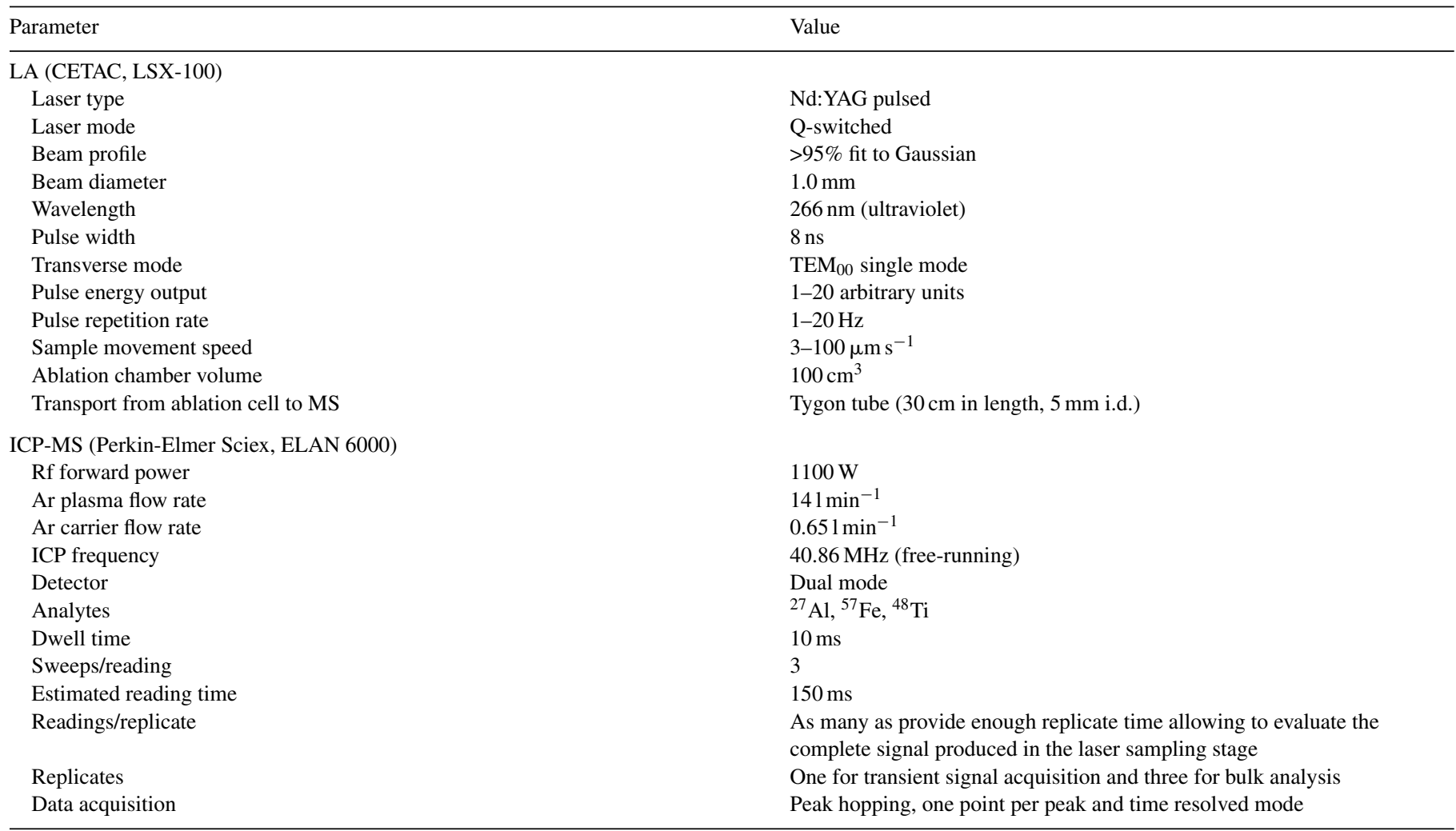


Table 3

Preparation and composition of glass samples (fused beads) for calibration

\begin{tabular}{|c|c|c|c|c|c|c|c|}
\hline \multirow[t]{2}{*}{ Bead no. } & \multicolumn{4}{|c|}{ Starting material $(\mathrm{g})$} & \multicolumn{3}{|c|}{ Composition (\%) } \\
\hline & $\mathrm{Fe}_{2} \mathrm{O}_{3}$ & X3913 & $\mathrm{Al}_{2} \mathrm{O}_{3}$ & $\mathrm{TiO}_{2}$ & $\mathrm{Fe}$ & $\mathrm{Al}$ & $\mathrm{Ti}$ \\
\hline 0 & 0.250 & - & - & - & 2.2 & 0 & 0 \\
\hline 2 & 0.215 & 0.200 & - & - & 2.2 & 0.0098 & 0.0061 \\
\hline 3 & 0.160 & 0.500 & - & - & 2.2 & 0.0238 & 0.0149 \\
\hline 4 & 0.120 & 0.750 & - & - & 2.2 & 0.0349 & 0.0218 \\
\hline 7 & 0.250 & - & 0.0100 & 0.0100 & 2.2 & 0.0662 & 0.0748 \\
\hline 8 & 0.250 & - & 0.0150 & 0.0150 & 2.2 & 0.0992 & 0.1122 \\
\hline
\end{tabular}

A series of nine glass samples (fused beads) with fixed $\mathrm{Fe}$ content and different $\mathrm{Al}$ and $\mathrm{Ti}$ contents was prepared for calibration. Mixtures of appropriate amounts of $\mathrm{Fe}_{2} \mathrm{O}_{3}, \mathrm{Al}_{2} \mathrm{O}_{3}$ and $\mathrm{TiO}_{2}\left(99.9 \%\right.$, Aldrich) were melted in a Pt crucible at $1200^{\circ} \mathrm{C}$ for 5 min with $6 \mathrm{~g}$ of lithium tetraborate and $3 \mathrm{~g}$ of sodium carbonate. The molten mass was poured on to a platinum plate, preheated to dull red. To prepare the samples with low $\mathrm{Al}$ and $\mathrm{Ti}$ contents, and to avoid the addition of very small weights of oxides, appropriate quantities of the certified converted slag X3913 (AG der Dillinger Hüttenwerke, Dillinger, Germany), with certified contents of these elements $\left(\mathrm{Fe}=14.61 \% ; \mathrm{Al}_{2} \mathrm{O}_{3}=0.76 \%\right.$; $\mathrm{TiO}_{2}=0.42 \%$ ), were added. The amounts of starting materials and final composition of prepared beads are given in Table 3 . The weight of the beads was of $8 \pm 0.10 \mathrm{~g}$, whereas the total weight of materials used for preparation was $9.25 \mathrm{~g}$. The $\mathrm{Fe}, \mathrm{Al}$ and Ti contents were calculated considering the real weight of the obtained glasses $(8 \mathrm{~g})$, assuming that the weight loss is due to the $\mathrm{CO}_{2}$ detachment from the $3 \mathrm{~g}$ of sodium carbonate used in the fusion.

\subsection{Procedure}

Experiments were done using the following laser sampling modes: single point (laser is fired repetitively over a single position of the sample), line scan (the sample is moving horizontally at a constant speed) and rastering (several discrete single spots are consecutively performed, with a specific number of laser pulses on each spot and a specific distance between spots). The optimization of the laser operating parameters was performed using the pure electrolytic iron BAM 098-1. The laser pulse energy was selected in the range from 6 to 10 (arbitrary units), corresponding to values ranging from 0.6 to $4 \mathrm{~mJ} \mathrm{pulse}^{-1}$ (energies measured with a laser power/energy meter model EM 400 from Molectron Detector, Inc., USA). As a good spatial resolution requires small spot size, the laser beam was always focused at the sample surface, in order to work with the smallest crater diameter attainable. A pulse repetition rate of $5 \mathrm{~Hz}$ was used for all tests, except for the in-depth analysis, where the pulse repetition rate was increased progressively $(1 \mathrm{~Hz}$ for the first scan, $2 \mathrm{~Hz}$ for the two followings, and $4 \mathrm{~Hz}$ for the two last). The error bars in the plots represent standard deviation values based on four replicates.

\section{Results and discussion}

\subsection{Influence of laser operating parameters}

In LA-ICP-MS analysis, spatial resolution in all three dimensions is theoretically limited by the ablation rate and crater aspect ratio (depth/diameter ratio of the crater) for depth profiling (discrete spots, or single point laser sampling mode) and by the depth and width of the track for lateral profiling (line scan laser sampling mode). By maintaining laser source, focusing conditions and pulse repetition rate constant, all these parameters depend on the laser pulse energy. Crater aspect ratio and depth of the track also depend on the number of laser pulses and scan speed, respectively. On the other hand, the intensity of the measured transient analytical signal is a result of the sum of weighted responses of neighbouring ablation pulses. Hence, the effect of laser pulse energy, number of laser pulses, depth and width of crater and track and scan speed on the analyte signal response has been studied, in order to obtain the best laser operating conditions.

The influence of laser irradiance on analyte signal response was tested for laser pulse energies of $0.6,1.5,2.5,3.3$ and $4.0 \mathrm{~mJ}$, resulting in irradiance values of $10,15,17,19$ and $21 \mathrm{GW} \mathrm{cm}^{-2}$, respectively. Fig. 1 shows the dependence of the normalized analyte signal response, which corresponds directly to the quantity of mass ablated, with the number of laser pulses for the dif-

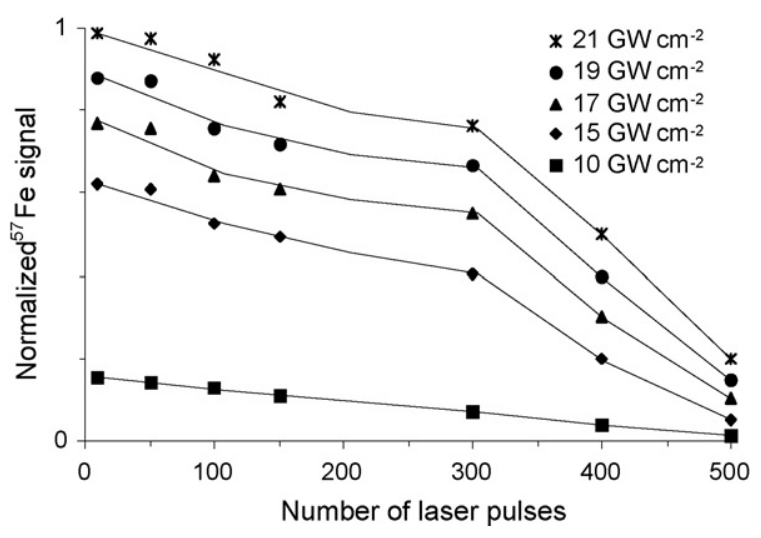

Fig. 1. Influence of number of laser pulses on normalized ${ }^{57} \mathrm{Fe}$ signal for irradiance values ranging from 10 to $21 \mathrm{GW} \mathrm{cm}^{-2}$. Sample: CRM BAM 098-1. 
ferent laser pulse energies. As expected, the higher the energy, the higher the analyte signal response. On the other hand, it can be observed that, during progressive ablation, the analyte signal remains nearly constant by the first 50 pulses. Between 50 and 150 pulses, it decreases sharply to about $80 \%$ of the initial response, even with the highest irradiance $\left(21 \mathrm{GW} \mathrm{cm}^{-2}\right)$.

Between 150 and 300 pulses, there is a very gradual decay of the signal, falling down later dramatically. This behaviour can be explained, according to Tokarev et al. [29] by the threedimensional plasma expansion that takes place in the surface and in the shallow craters, which implies a more significant material removal, and by the one-dimensional expansion inside the deep craters, where there is practically no material removal due to dense plasma and strong laser beam attenuation. In addition, both the defocusing and the cone-shaped crater development, can also contribute to a decreasing signal with increasing number of laser pulses, especially for higher laser pulse energies.

As a compromise between ion signal intensity and crater diameter, a laser pulse energy of $1.5 \mathrm{~mJ}$, providing a good sensitivity and a crater diameter of $40 \mu \mathrm{m}\left(I=15 \mathrm{GW} \mathrm{cm}^{-2}\right)$, was selected for further experiments. Bleiner et al. [30] studied the influence of irradiance in crater morphology for different metals $(\mathrm{Al}, \mathrm{Cu}, \mathrm{Fe}, \mathrm{Zn}, \mathrm{Mn}, \mathrm{Co})$ showing that at low irradiance the crater morphology did not develop uniformly and the reproducibility of the micro-sampling becomes poor, whereas at high irradiance a more regular pan-shaped morphology was produced and a more efficient material removal mechanism is attained. The dependence of crater aspect ratio (depth/width) on number of laser pulses, for the selected laser pulse energy $(1.5 \mathrm{~mJ})$, was also assessed. In agreement with our previous results [14], the diameter at the top of the crater remained nearly constant $(\approx 40 \mu \mathrm{m})$, whereas the crater depth increased linearly from about 1 to $140 \mu \mathrm{m}$ when the number of laser pulses increased from 1 to $150 \mu \mathrm{m}$. This corresponds to an ablation rate of approximately $1 \mu \mathrm{m}$ per pulse. Fig. 2 illustrates the variation of the normalized analyte signal response wit the crater aspect ratio. As can be seen, the signal response clearly decreases for crater aspect ratios higher than 1.0 , dropping to about $80 \%$ of the initial signal response for values of about 3.5. Consequently, a crater aspect

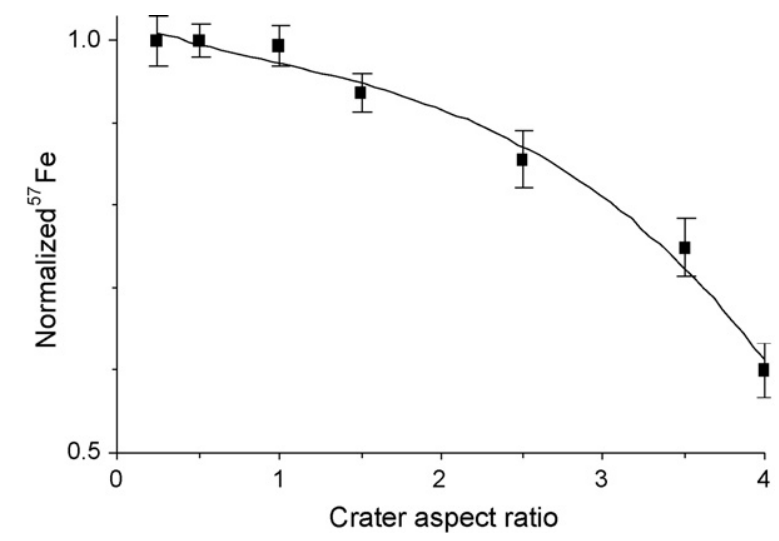

Fig. 2. Influence of crater aspect ratio on normalized ${ }^{57} \mathrm{Fe}$ signal. Sample: CRM BAM 098-1. Laser sampling mode: single point; laser pulse energy: $1.5 \mathrm{~mJ}$; pulse repetition rate: $5 \mathrm{~Hz}$; irradiance: $15 \mathrm{GW} \mathrm{cm}^{-2}$.

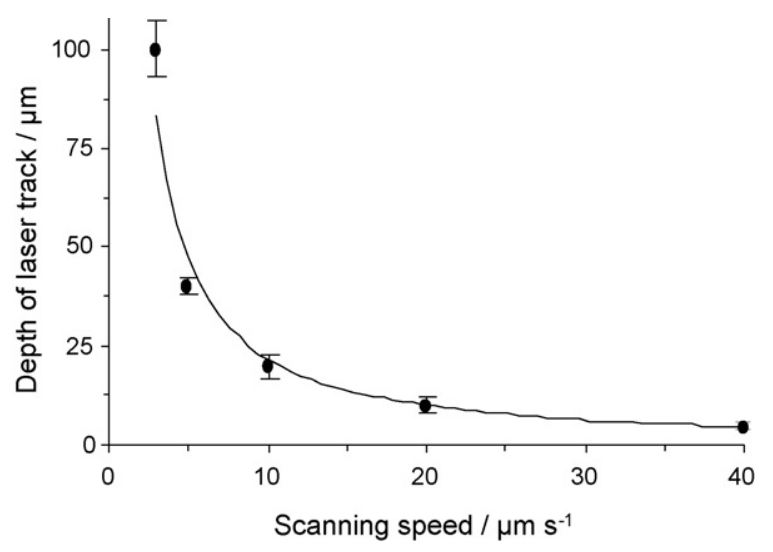

Fig. 3. Influence of scanning speed on depth of laser track. Sample: CRM BAM 098-1. Laser sampling mode: line scan; laser pulse energy: $1.5 \mathrm{~mJ}$; pulse repletion rate: $5 \mathrm{~Hz}$

ratio value of $c a$. 1, which is obtained by firing the sample with about 40 laser pulses, was chosen for further tests.

The effect of scanning speed on depth of laser track was studied for $2,5,10,20$, and $40 \mu \mathrm{m} \mathrm{s}^{-1}$ by using the line scan laser sampling mode. The applied laser pulse energy was the selected value of $1.5 \mathrm{~mJ}$, so the width of laser track was about $40 \mu \mathrm{m}$ in all cases. The results are depicted in Fig. 3. As can be seen, for fixed laser conditions the track depth varies inversely with scanning speed. A scanning speed of $5 \mu \mathrm{m} \mathrm{s}^{-1}$ is required to achieve a laser track with a depth/width ratio of $c a$. 1 (i.e., a laser track of about $40 \mu \mathrm{m}$ both in width and depth), so this scanning speed value was selected for all further lateral profiling analysis. Taking into account an ablation rate of $1 \mu \mathrm{m}$ pulse $\mathrm{p}^{-1}$, the laser track should reach a uniform and unvarying depth of $c a .40 \mu \mathrm{m}$ after about $8 \mathrm{~s}$ of line scanning (i.e., 40 laser pulses, at a pulse repetition rate of $5 \mathrm{~Hz}$ ). Fig. 4 shows the temporal behaviour of the ${ }^{57} \mathrm{Fe}$ signal by using the line scan laser sampling mode and the selected optimal conditions (laser irradiance $1.5 \mathrm{~mJ}$, repetition rate $5 \mathrm{~Hz}$, and scanning speed $5 \mu \mathrm{m} \mathrm{s}^{-1}$ ). As can be observed, the ${ }^{57} \mathrm{Fe}$ signal reaches a maximum intensity when ablation starts and, immediately, it drops slowly for about $8 \mathrm{~s}$. This behaviour can be related with the three-dimensional plasma expansion during the firsts pulses, and with the gradual increasing of depth of

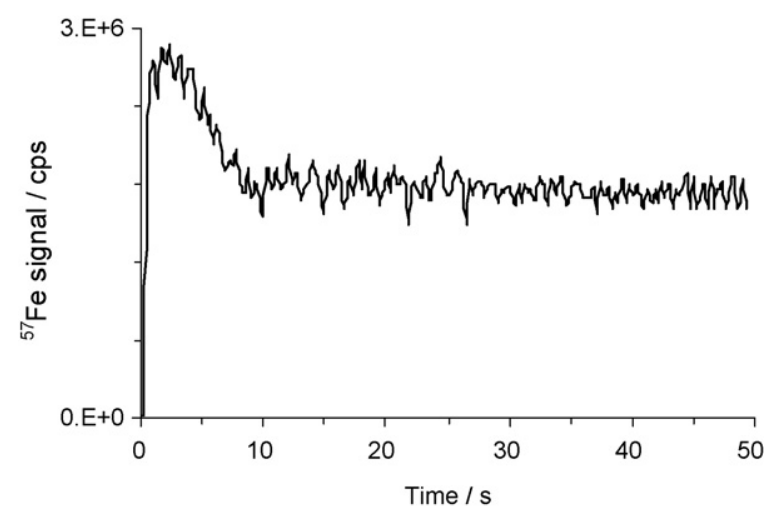

Fig. 4. Temporal behaviour of raw ${ }^{57} \mathrm{Fe}$ signal in CRM BAM 098-1 sample. Laser sampling mode: line scan; laser pulse energy: $1.5 \mathrm{~mJ}$; pulse repetition rate: $5 \mathrm{~Hz}$; scanning speed: $5 \mu \mathrm{m} \mathrm{s}^{-1}$. 

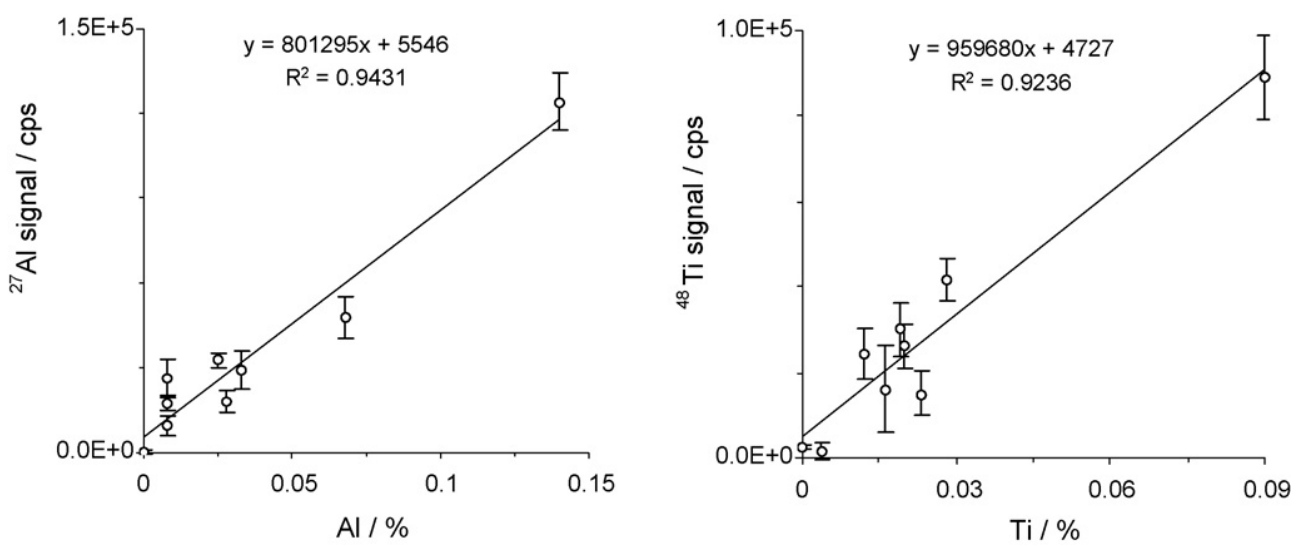

Fig. 5. Correlation between mean ion intensity values and certified content for $\mathrm{Al}$ (left) and Ti (right) in CRM steel samples. Laser sampling mode: line scan; laser pulse energy: $1.5 \mathrm{~mJ}$; pulse repetition rate: $5 \mathrm{~Hz}$; number of laser pulses: 400 ; scanning speed: $5 \mu \mathrm{m} \mathrm{s}^{-1}$; scanning length: $400 \mu \mathrm{m}$; preablation time: $20 \mathrm{~s}$.

the laser track until 40 pulses were fired. From $c a .8$ to $50 \mathrm{~s}$ (i.e. $40-250$ pulses), the signal reaches a plateau which is associated with the uniform depth of the laser track $(c a .40 \mu \mathrm{m})$; therefore, the sample must be preablated during at least $8 \mathrm{~s}$, in order to obtain a completely stabilized signal. This behaviour agrees with the dependence of signal intensity on crater aspect ratio, presented in Fig. 2. As crater aspect ratio increased, the ion signal intensity decreased, reaching a stable value when the crater aspect ratio remained constant. This behaviour is in agreement with the effects of crater development on signal intensity presented by Borisov et al. [31].

\subsection{Calibration graphs}

Before establishing the calibration graphs, the $\mathrm{Al}$ and Ti signals behaviour of the CRM steel samples listed in Table 2, as well as the CRM BAM 098-1 (which was used as a blank), was evaluated. The samples were ablated for $80 \mathrm{~s}$ (i.e., 400 laser pulses) by using the line scan laser sampling mode and the optimized laser operating parameters (laser pulse energy $1.5 \mathrm{~mJ}$, scanning speed $5 \mu \mathrm{m} \mathrm{s}^{-1}$, and preablation time $20 \mathrm{~s}$ ). Fig. 5 shows the correlation between mean ion intensity values and $\mathrm{Al}$ and Ti certified content. As can be observed, a poor signal-concentration correlation (see the low regression coefficients in Fig. 5) and large standard deviation values are attained. Taking into account the high similarity of the matrix in all CRMs (excepting in JK 37 sample), the rather poor linearity could be associated with an inhomogeneous distribution of the $\mathrm{Al}$ and $\mathrm{Ti}$ in the iron matrix.

In order to create the calibration graphs, the glass samples (fused beads) listed in Table 3 were ablated and analyzed by LA-ICP-MS under the same operating parameters as those used for steel samples. The correlation between mean ion intensity values and $\mathrm{Al}$ and Ti contents is illustrated in Fig. 6. As expected for a homogeneous material, a good linearity and low standard deviation values are obtained.

Comparing Figs. 5 and 6, it can be observed that the ion signals are approximately three times higher in the fused bead samples than in the steel samples, with significantly lower standard deviations and better linearity. Differences in the ablation yield resulting from differences in target matrix (differences in the mass of the ablated sample relative to the metal and glass samples, i.e. ablation efficiency) can be compensated by the use of internal standardization, which would fit ion signals from metal and glass samples. Hence, as $\mathrm{Fe}$ is the matrix element in the CRM steel samples (98-99\% for all of them, except for JK 37 sample with a $\mathrm{Fe}$ content of about $40 \%$ ) and it has a constant content in the prepared fused beads (Table 3), this element was chosen as internal standard. Considering the large
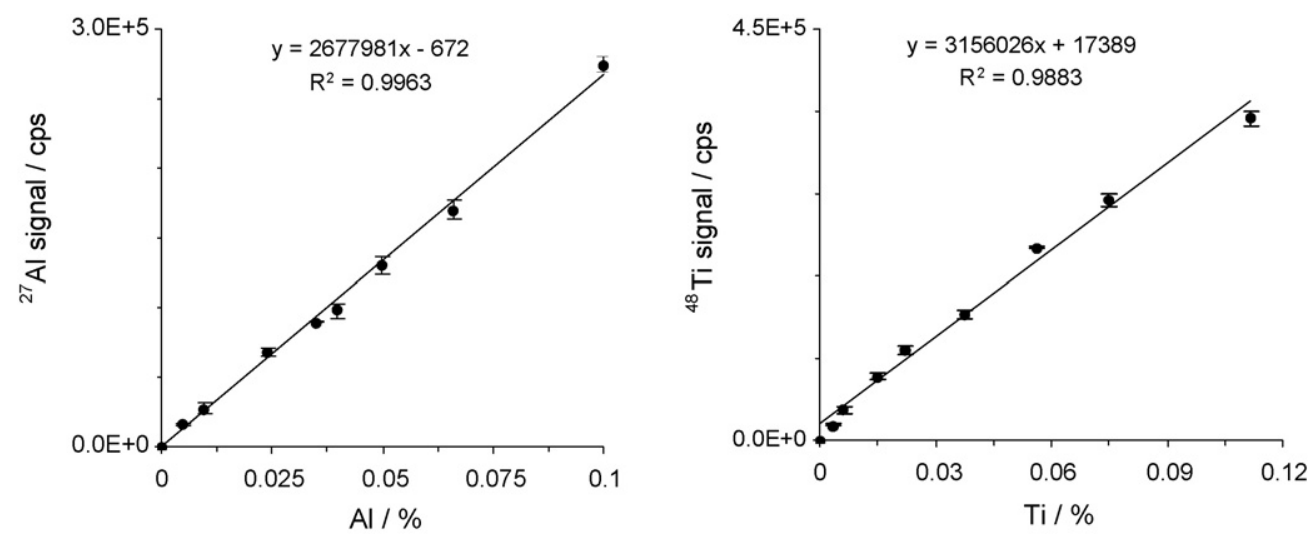

Fig. 6. Calibration graphs for $\mathrm{Al}$ (left) and Ti (right) in fused beads. Laser sampling mode: line scan; laser pulse energy: $1.5 \mathrm{~mJ}$; pulse repetition rate: $5 \mathrm{~Hz}$; number of laser pulses: 400 ; scanning speed: $5 \mu \mathrm{m} \mathrm{s}^{-1}$; scanning length: $400 \mu \mathrm{m}$; preablation time: $20 \mathrm{~s}$. 

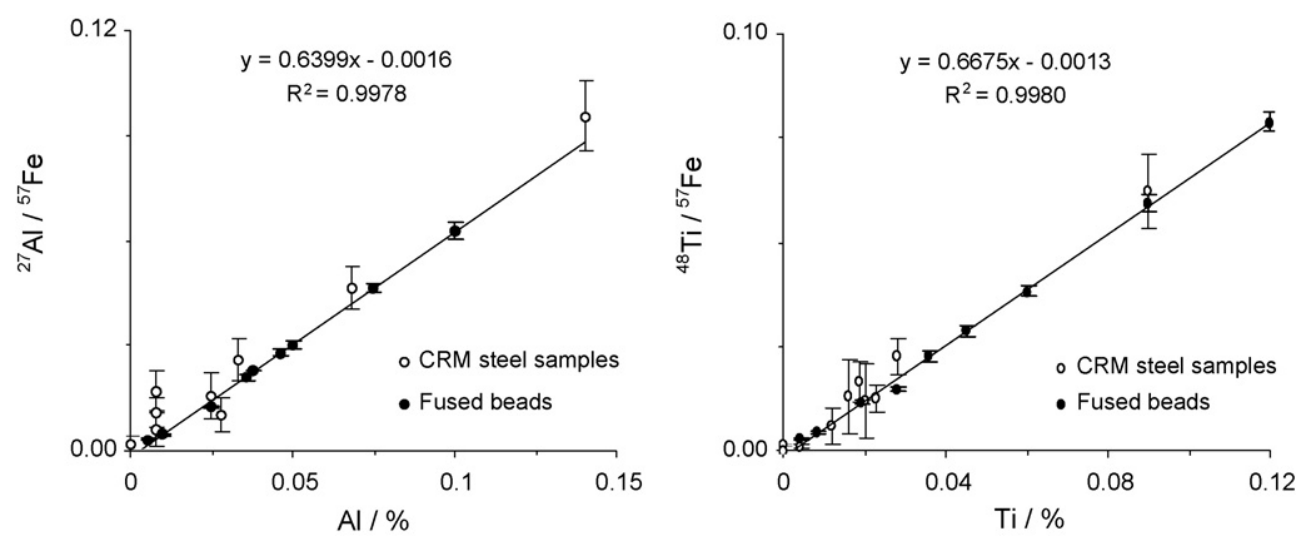

Fig. 7. Calibration graphs for $\mathrm{Al}$ (left) and Ti (right) in fused beads, using ${ }^{57} \mathrm{Fe}$ as internal standard. Ratio signals for CRM steel samples are included. Laser sampling mode: line scan; laser pulse energy: $1.5 \mathrm{~mJ}$; pulse repetition rate: $5 \mathrm{~Hz}$; number of laser pulses: 400 ; scanning speed: $5 \mu \mathrm{m} \mathrm{s}^{-1}$; scanning length: $400 \mu \mathrm{m}$; preablation time: $20 \mathrm{~s}$.

linear dynamic concentration range of the ICP-MS technique, the $\mathrm{Fe}$ signal value from the $2.2 \%$ of $\mathrm{Fe}$ content in the beads (about $8 \times 10^{4} \mathrm{cps}$ ) was extrapolated to the value that should correspond to a $100 \%$ of $\mathrm{Fe}\left(8 \times 10^{4} \times 100 / 2.2=36 \times 10^{5}\right)$. This value $\left(36 \times 10^{5}\right)$ is three times higher than the $\mathrm{Fe}$ signal for the CRM steel samples ( $\left.c a .12 \times 10^{5} \mathrm{cps}\right)$. That is, the signal of both analytes $(\mathrm{Al}$ and $\mathrm{Ti})$ and of the internal standard $(\mathrm{Fe})$ is three times higher for the calibration standards (glasses) than for the steel samples (CRMs). The Fe signal of JK 37 high alloy steel sample was also correlated to $100 \%$. Consequently, using $\mathrm{Al} / \mathrm{Fe}$ and $\mathrm{Ti} / \mathrm{Fe}$ ratio signals (providing that the $\mathrm{Fe}$ signals are those which would correspond to a $100 \%$ of this element), the values from beads and from steel samples, with similar $\mathrm{Al}$ or $\mathrm{Ti}$
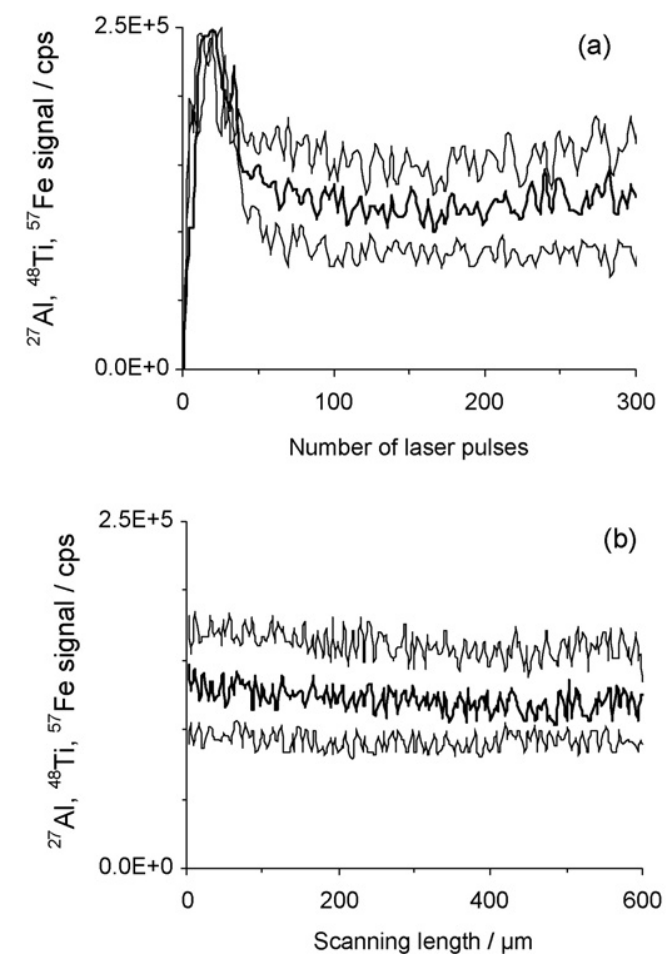

content, should be comparables. Then, the calibration graphs, for $\mathrm{Al}$ and Ti determination in steel samples, can be constructed by normalizing the ${ }^{27} \mathrm{Al}$ and ${ }^{48} \mathrm{Ti}$ signals of the glass samples to the signal that would correspond to a $100 \%$ of Fe. The obtained plots, from the beads samples listed in Table 3, are depicted in Fig. 7. The ${ }^{27} \mathrm{Al} /{ }^{57} \mathrm{Fe}$ and ${ }^{48} \mathrm{Ti} /{ }^{57} \mathrm{Fe}$ ratio values for the CRM steel samples are included, only in order to know their coincidence with the linear fit of the calibration graph, but they have not been considered to calculate the regression coefficients. As can be observed, the use of this approach makes possible to compare the ablation yield for both types of samples. However, the use of ratio signals does not improve the standard deviation of the $\mathrm{Al}$ and Ti values in the CRM metal samples (they remain simi-
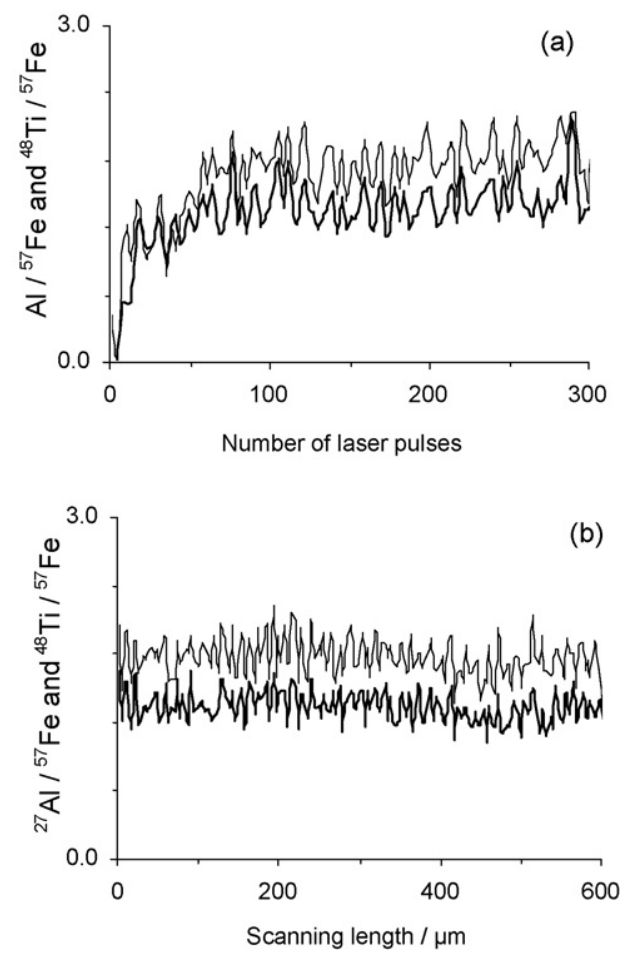

Fig. 8. Temporal behaviour of raw (left) and normalized (right) ${ }^{27} \mathrm{Al}$ (strong line), ${ }^{48} \mathrm{Ti}$ (soft line) and ${ }^{57} \mathrm{Fe}$ (dotted line) signals in a glass sample (fused bead no. 6 in Table 3). (a) Laser sampling mode: single point; number of laser pulses: 300. (b) Laser sampling mode: line scan; scanning speed: $5 \mu \mathrm{m} \mathrm{s}{ }^{-1}$; scanning length: $600 \mu \mathrm{m}$, after a preablation time of $20 \mathrm{~s}$. Laser pulse energy: $1.5 \mathrm{~mJ}$; pulse repetition rate: $5 \mathrm{~Hz}$. 

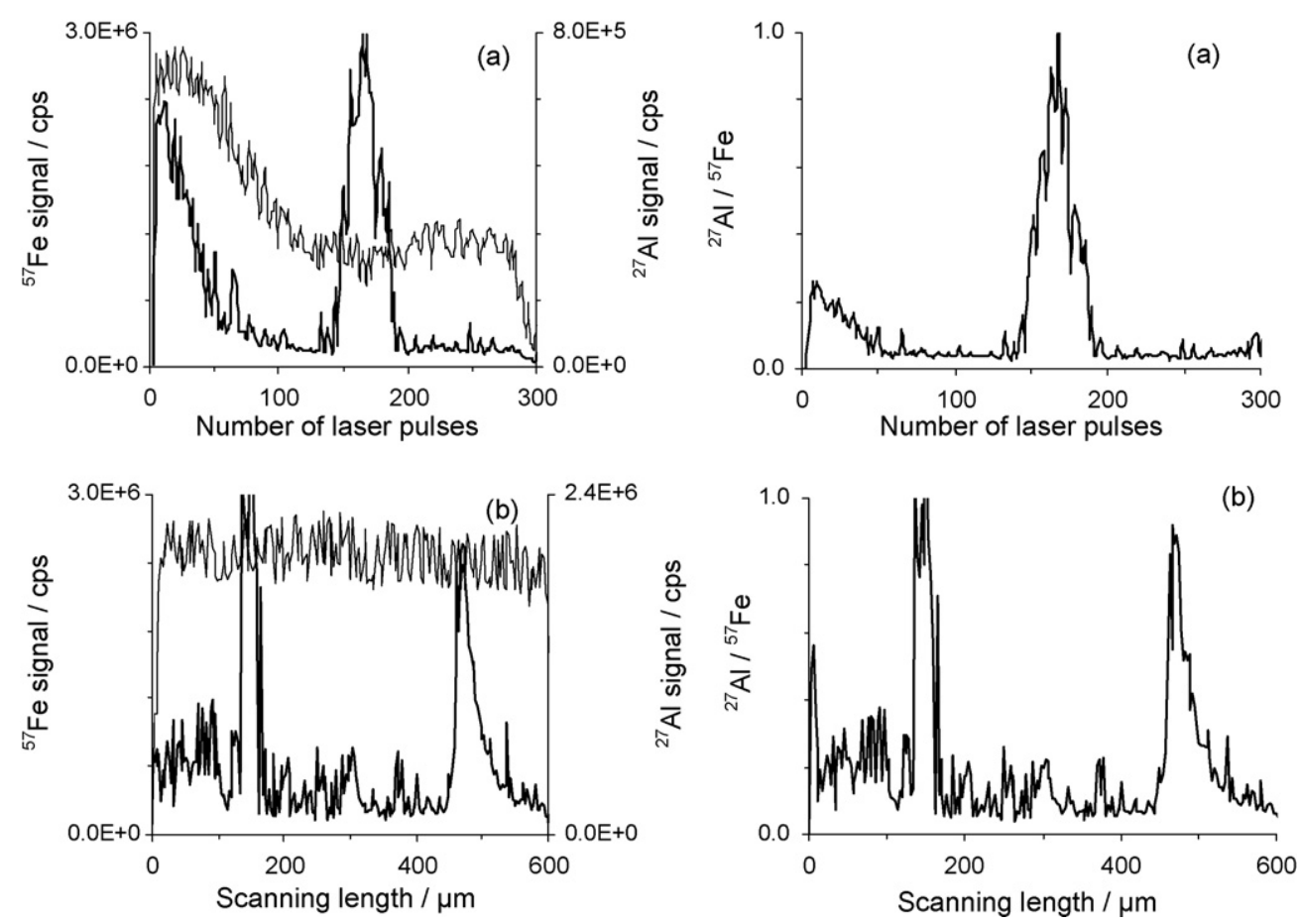

Fig. 9. Temporal behaviour of raw (left) and normalized (right) ${ }^{27} \mathrm{Al}$ (strong line) and ${ }^{57} \mathrm{Fe}$ (soft line) signals in CRM SS-458 carbon steel sample for a spot (a) and a line scan (b). (a) Laser sampling mode: single point; number of laser pulses: 300 . (b) Laser sampling mode: line scan; scanning speed: $5 \mu \mathrm{m} \mathrm{s}{ }^{-1}$; scanning length: $600 \mu \mathrm{m}$, after a preablation time of $20 \mathrm{~s}$. Laser pulse energy: $1.5 \mathrm{~mJ}$; pulse repetition rate: $5 \mathrm{~Hz}$.
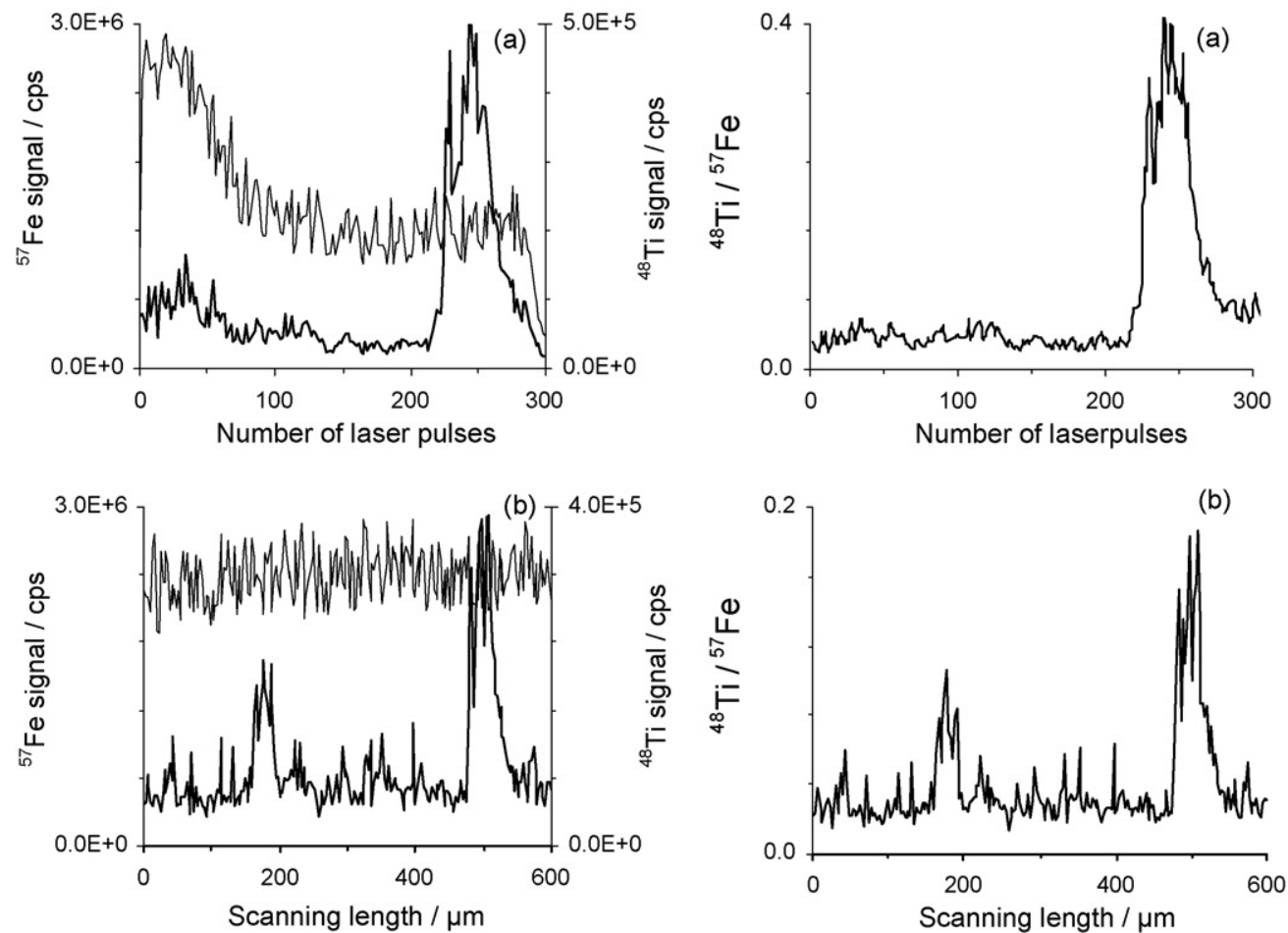

Fig. 10. Temporal behaviour of raw (left) and normalized (right) ${ }^{48} \mathrm{Ti}$ (strong line) and ${ }^{57} \mathrm{Fe}$ (soft line) signals in CRM SS-451 carbon steel sample for a spot (a) and a line scan (b). (a) Laser sampling mode: single point; number of laser pulses: 300 . (b) Laser sampling mode: line scan; scanning speed: $5 \mu \mathrm{m} \mathrm{s}{ }^{-1}$; scanning length: $600 \mu \mathrm{m}$, after a preablation time of $20 \mathrm{~s}$. Laser pulse energy: $1.5 \mathrm{~mJ}$; pulse repetition rate: $5 \mathrm{~Hz}$. 
lar and some times higher that when using raw signals, Fig. 5), which proves that the dispersion found in the results is mainly due to the heterogeneous distribution of the insoluble fractions of $\mathrm{Al}$ and $\mathrm{Ti}$.

\subsection{Spatial distribution of Al and Ti in steel samples}

To study the spatial distribution of $\mathrm{Al}$ and $\mathrm{Ti}$ in the CRM steel samples, several zones were examined for both single point (300 laser pulses) and line scan ( $600 \mu \mathrm{m}$ of length, after a preablation time of $20 \mathrm{~s}$ ) laser sampling modes. Normalization of the raw signals was used to eliminate the variations associated with the crater development in single spot and the fluctuations related with the track growth in line scan. In the graphics, both raw and normalized signals were plotted. Firstly, for comparative purpose, the temporal behaviour of $\mathrm{Al}, \mathrm{Ti}$ and $\mathrm{Fe}$ signals for a homogeneous glass sample (the fused bead no. 6 in Table 3 ) was studied. The results are shown in Fig. 8. In the plot corresponding to a single spot (Fig. 8a), a different behaviour was found between raw and normalized signals during the firsts pulses. In the temporal behaviour of the raw signals, after a peak associated with the surface three-dimensional plasma expansion, a steadystate appears. In the normalized signals, during the first pulses (associated to the peak) the $\mathrm{Al} / \mathrm{Fe}$ and $\mathrm{Ti} / \mathrm{Fe}$ ratios were different than those of the steady state. This behaviour can be attributed to variations in mass entrainment/transport efficiency, probably due to differences in particle size distribution during ablation at a fresh sample surface and after the crater was developed. After stabilization of the signals, a steady state appears, from 40 to 300 pulses, this proving the homogeneous distribution of $\mathrm{Al}$ and $\mathrm{Ti}$ along the crater depth. The plot corresponding to the line scan (Fig. 8b) shows stable signals along the whole line, which demonstrates the homogeneous distribution of $\mathrm{Al}$ and $\mathrm{Ti}$ in the surface. The ${ }^{27} \mathrm{Al}$ and ${ }^{57} \mathrm{Fe}$ ion intensity charts for CRM SS-458 sample corresponding to a single spot and a line scan, in a heterogeneous zone, are shown in Fig. 9; similar charts for ${ }^{48} \mathrm{Ti}$ and ${ }^{57} \mathrm{Fe}$ in CRM SS-451 sample are illustrated in Fig. 10. In both figures, the trend of the ${ }^{57} \mathrm{Fe}$ signal is analogous in all cases to that of the glass sample, as expected for an element homogeneously distributed in the samples, whereas the behaviour of the ${ }^{27} \mathrm{Al}$ and ${ }^{48} \mathrm{Ti}$ signals is quite different. Nevertheless, when ablating zones with a homogeneous $\mathrm{Al}$ and $\mathrm{Ti}$ distribution, the time resolved signals of these elements do not present differentiated peaks, showing a similar trend to that observed in Fig. 8 for the glass samples".

Al signal in Fig. 9 and Ti signal in Fig. 10, show substantial variations with a very similar shape in both raw and normalized plots, which proves that these variations can be attributed to the

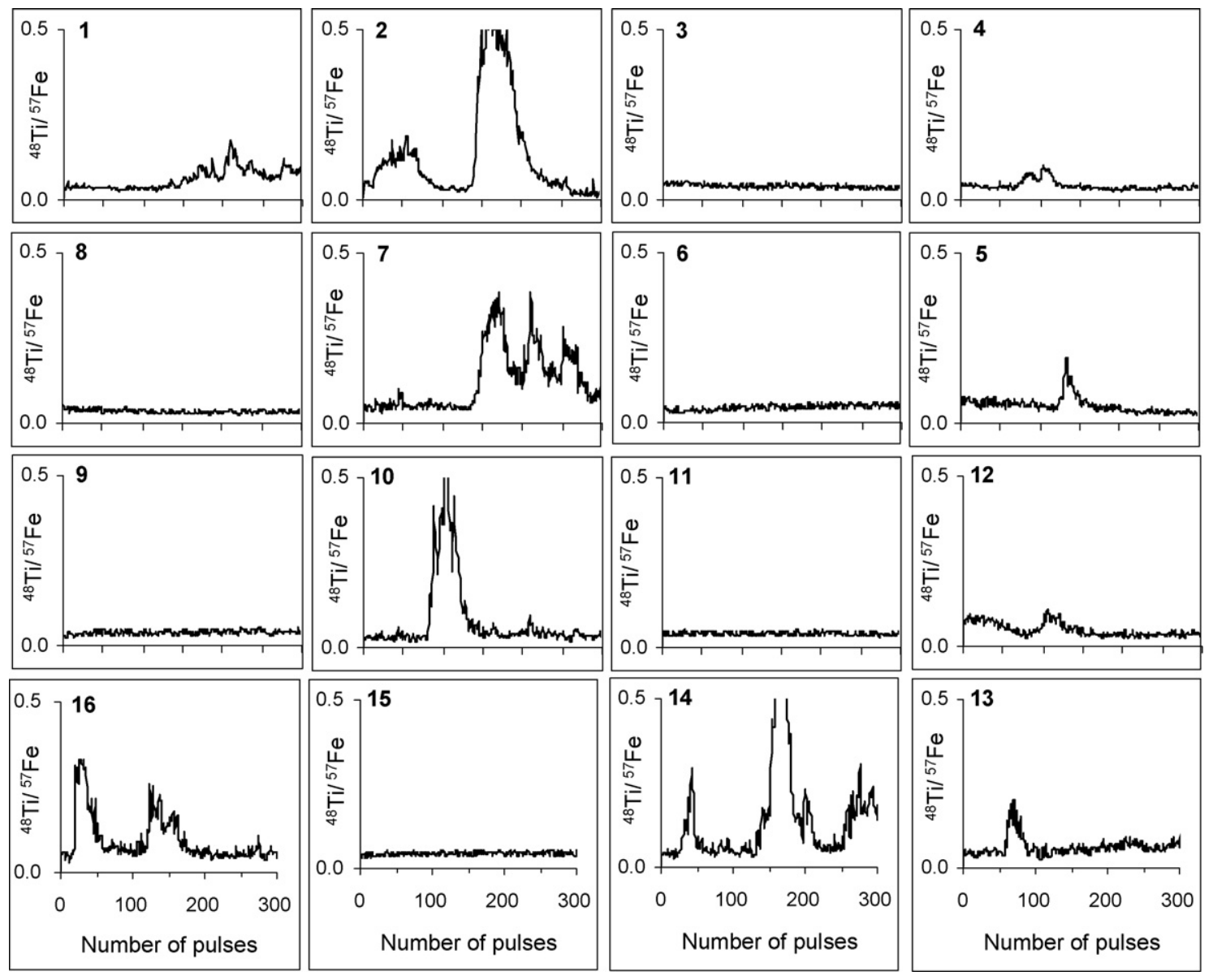

Fig. 11. Temporal behaviour of normalized ${ }^{48} \mathrm{Ti}$ signals for 16 different spots (distributed in four rows, with four spots in each row) in an inclusion zone $(175 \mu \mathrm{m} \times 175 \mu \mathrm{m})$ of CRM SS-451 carbon steel sample. Laser sampling mode: rastering; number of laser pulses: 300 for each spot; distance between spots (both in horizontal and in vertical direction): $45 \mu \mathrm{m}$; laser pulse energy: $1.5 \mathrm{~mJ}$; pulse repetition rate: $5 \mathrm{~Hz}$. 

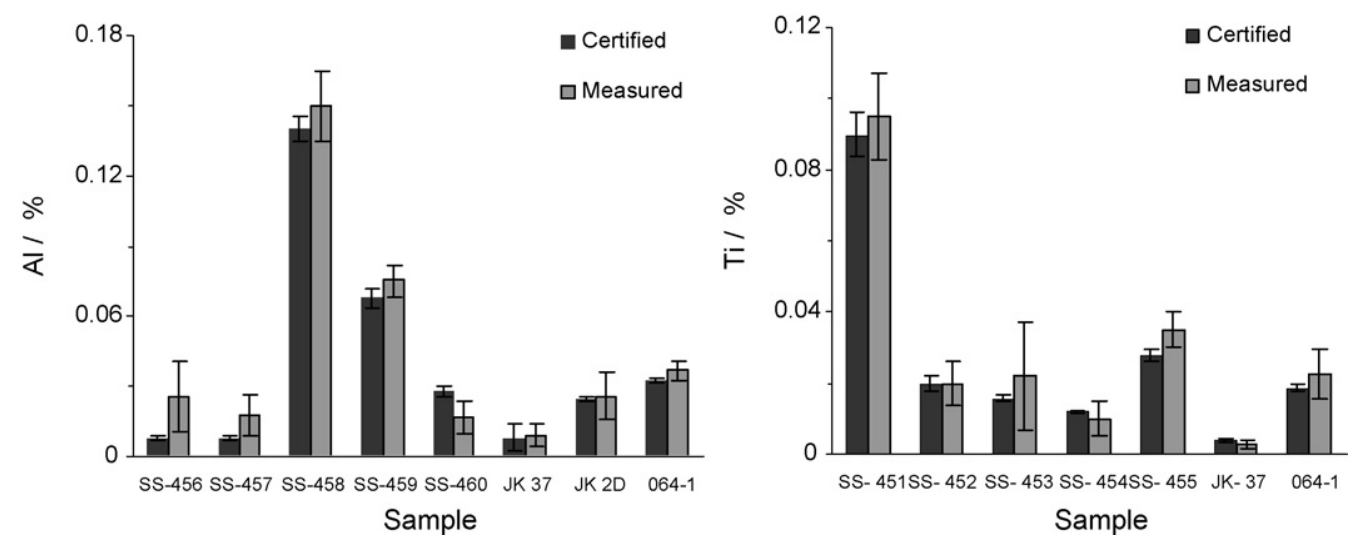

Fig. 12. Analytical results obtained for Al (left) and Ti (right) in CRM steel samples. Quantification was carried out by using the fused bead calibration graphs depicted in Fig. 7 and ${ }^{57} \mathrm{Fe}$ as internal standard. Laser experimental conditions as in Fig. 8.

heterogeneous distribution of the $\mathrm{Al}$ and $\mathrm{Ti}$ insoluble fractions. Fig. 9a shows a well-differentiated peak of ${ }^{27} \mathrm{Al}$ that appears after firing 150 laser pulses that demonstrates the presence of an inclusion of $\mathrm{Al}$ at a position of $c a .150 \mu \mathrm{m}$ below the sample surface (taking into account an ablation rate of $1 \mu \mathrm{m}$ pulse $\mathrm{s}^{-1}$ ). The line scan reveals the existence at the surface of a zone rich in $\mathrm{Al}$ between 0 and $100 \mu \mathrm{m}$ and two inclusions at about 150 and $450 \mu \mathrm{m}$ (Fig. 9b). The wide peak of ${ }^{48}$ Ti shown in Fig. 10a can be attributed to a thick inclusion located at a depth of $c a$. $225 \mu \mathrm{m}$. The line scan illustrates the presence at the surface of two inclusions of Ti at about 150 and $475 \mu \mathrm{m}$ (Fig. 10b).

In addition, a heterogeneous area of $175 \mu \mathrm{m} \times 175 \mu \mathrm{m}$ was examined for $\mathrm{Ti}$ in the CRM SS-451 carbon steel sample using rastering mode for laser sampling. In the selected area, 16 single spots were performed, with 300 laser pulses fired on each spot. The 16 spots were distributed in four rows, with four spots in each row. The distance between spots, both in horizontal and in vertical direction, was $45 \mu \mathrm{m}$. Fig. 11 presents the ${ }^{48} \mathrm{Ti}$ transient signals (normalized to ${ }^{57} \mathrm{Fe}$ ) corresponding to each spot. As can be seen, there are no peaks (i.e., insoluble inclusions) in spots $3,6,8,9,11$ and 15 , whereas the peaks that appear in the other spots reveal the existence of Ti heterogeneities at the surface and inside the sample.

\subsection{Bulk analysis}

Calibration graphs obtained from fused beads (Fig. 7) were used to determine the concentration of total $\mathrm{Al}$ and $\mathrm{Ti}$ in the
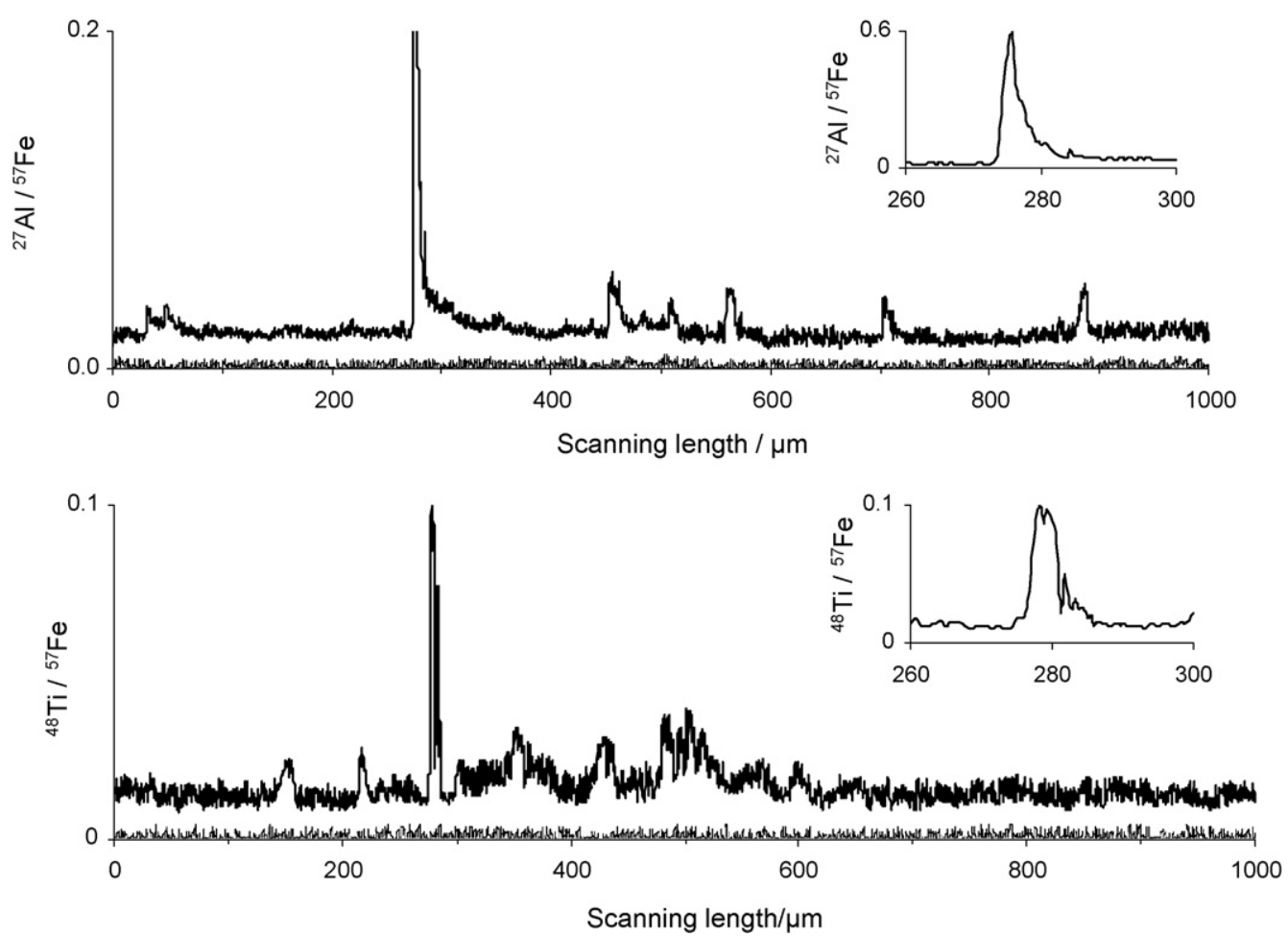

Fig. 13. Temporal behaviour of normalized ${ }^{27} \mathrm{Al}$ and ${ }^{48} \mathrm{Ti}$ signals in CRM 064-1 Nb/Ti interstitial free steel (strong line) and CRM BAM 098-1 pure electrolytic iron (soft line) samples. Insets: detail of the 260-300 $\mu \mathrm{m}$ interval of scanning length. Laser sampling mode: line scan; laser pulse energy: $1.5 \mathrm{~mJ}$; pulse repetition rate: $5 \mathrm{~Hz}$; scanning speed: $5 \mu \mathrm{m} \mathrm{s}^{-1}$; scanning length: $1000 \mu \mathrm{m}$, after a preablation time of $20 \mathrm{~s}$. 
CRM steel samples listed in Table 2. The analytical results are included in Fig. 12. As can be seen, the measured concentrations correspond with the certified values within the experimental uncertainty. Only for Al in SS-456 and SS-457 samples the results were not entirely satisfactory, which could be attributed to the low Al concentration $(0.008 \%)$, together with its heterogeneous distribution. However, the results obtained for $\mathrm{Al}$ (and also for Ti) in JK 37 sample are in good agreement in spite of their low content $(0.0084 \%$ for $\mathrm{Al}$ and $0.0039 \%$ for $\mathrm{Ti})$. A possible explanation to account for this is that the $\mathrm{Al}$ and $\mathrm{Ti}$ distribution in JK 37 sample (in fact, a high alloy steel with a Fe content of about $40 \%$ ) is very probably more homogeneous than in SS samples (carbon steels with a Fe content of 98-99\%).

From these results it is clear that, in spite of the heterogeneous distribution of $\mathrm{Al}$ and $\mathrm{Ti}$ in the CRM steel samples, laser sampling by line scan and calibration with synthetic fused beads can provide, after an optimization of laser operating parameters, an acceptable approach for bulk quantitative analysis by LA-ICPMS.

\subsection{Determination of soluble and total Al and Ti}

The determination of soluble and total $\mathrm{Al}$ and $\mathrm{Ti}$ was performed on the CRM 064-1 ( $\mathrm{Nb} / \mathrm{Ti}$ interstitial free steel) sample with certified values (Table 2) for total and soluble $\mathrm{Al}$ and for total Ti. CRM BAM 098-1 (pure electrolytic iron) sample was used as a blank. ${ }^{57} \mathrm{Fe}$ was used as internal standard. The line scan laser sampling mode and the optimized laser operating parameters (laser pulse energy of $1.5 \mathrm{~mJ}$, scanning speed of $5 \mu \mathrm{m} \mathrm{s}^{-1}$ and preablation time of $20 \mathrm{~s}$ ) were employed. The calibration graphs obtained from fused beads (Fig. 8) were used. The analytical determinations were performed at the sample surface and in-depth.

For the analysis at the sample surface, four line scans of $1000 \mu \mathrm{m}$ length were carried out at four different positions chosen at random. The normalized ${ }^{27} \mathrm{Al}$ and ${ }^{48} \mathrm{Ti}$ ion intensity charts attained for one of the line scans are illustrated, as an example, in Fig. 13. The ablated zone shows a clear heterogeneity, fundamentally between 250 and $600 \mu \mathrm{m}$. For the in-depth analysis, four tests, each one consisting of five successive scans on the same line ( $300 \mu \mathrm{m}$ length), at four different positions chosen at random, were carried out. In order to reach a depth of laser track of about 10-12 $\mu \mathrm{m}$ for each scan, the pulse repetition rate was increased progressively: $1 \mathrm{~Hz}$ for the first scan, $2 \mathrm{~Hz}$ for the two followings, and $4 \mathrm{~Hz}$ for the two last. The normalized ${ }^{27} \mathrm{Al}$ and ${ }^{48} \mathrm{Ti}$ ion intensity charts attained for the five scans of one of the tests are plotted, as an example, in Fig. 14, where the cross-section SEM images of the laser track after each scan are also shown. The width of the laser track was $c a .40 \mu \mathrm{m}$, as expected, whereas the depth after each one of the five consecutive scans was about 12, 26, 37, 47 and $62 \mu \mathrm{m}$ (i.e., the depth/width ratio was in all cases lower than 1.5). A noticeable heterogeneous distribution of $\mathrm{Al}$ and $\mathrm{Ti}$ can be observed at depth.

The quantification was carried out from the normalized ${ }^{27} \mathrm{Al}$ and ${ }^{48} \mathrm{Ti}$ ion intensity values attained for the four line scans (analysis at the sample surface) and for the five successive scans of

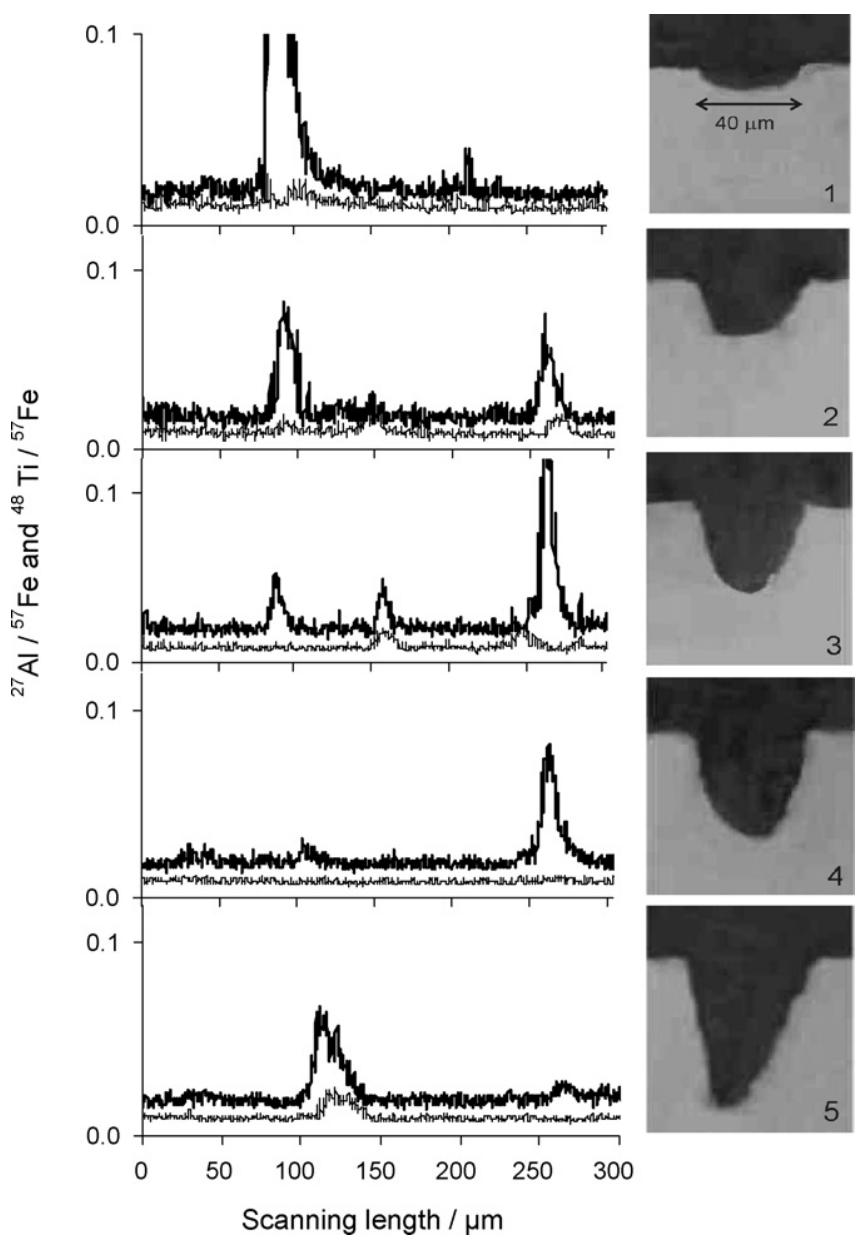

Fig. 14. Temporal behaviour of normalized ${ }^{27} \mathrm{Al}$ (strong line) and ${ }^{48} \mathrm{Ti}$ (soft line) signals in CRM 064-1 Nb/Ti interstitial free steel sample for five successive scans on the same line, and cross-section SEM images of the laser track after each scan. Laser sampling mode: line scan; laser pulse energy: $1.5 \mathrm{~mJ}$; pulse repetition rate: $1 \mathrm{~Hz}$ for the scan $1,2 \mathrm{~Hz}$ for the scans 2 and 3 , and $4 \mathrm{~Hz}$ for the scans 4 and 5; scanning speed: $5 \mu \mathrm{m} \mathrm{s}^{-1}$; scanning length: $300 \mu \mathrm{m}$, after a preablation time of $20 \mathrm{~s}$.

the four tests (in-depth analysis). It was considered that, for each scan, the average of all the net ion intensity values corresponded to the total element content. Similarly, the soluble element content was associated to the average of the net ion intensity values in the zones where no significant peaks appeared (e.g. in the case of Fig. 13, these zones would be the following scanning length intervals: 70-270, 590-690, 730-870, and 900-1000 $\mu \mathrm{m}$, for $\mathrm{Al} ; 0-130$ and $620-1000 \mu \mathrm{m}$, for Ti).

Fig. 15 shows the analytical results obtained for total and soluble $\mathrm{Al}$ and $\mathrm{Ti}$ at the sample surface (average of the results for the four line scans) and in depth (average of the results for the five successive scans of the four tests).

As can be seen, the values obtained by analysis at the sample surface for soluble and total Al concentration in CRM 064-1 differ significantly from each other and both values agree with the certified values. However, analytical results obtained for the in-depth analysis were not completely satisfactory because, although an acceptable concordance between certified and found values is obtained, a distinction cannot be made between soluble and total amount of Al. This can be due to the thermal effects 


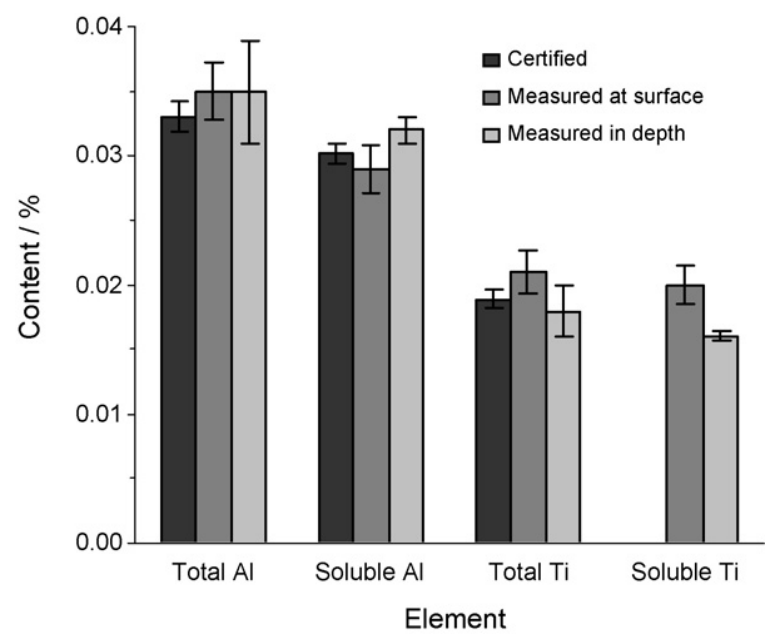

Fig. 15. Analytical results obtained for total and soluble $\mathrm{Al}$ and $\mathrm{Ti}$ at sample surface and in-depth in CRM 064-1 (Nb/Ti interstitial free steel) sample. Quantification was carried out by using the fused bead calibration graphs depicted in Fig. 7 and ${ }^{57} \mathrm{Fe}$ as internal standard. Laser experimental conditions for the analysis at sample surface as in Fig. 13, and for the in-depth analysis as in Fig. 14.

associated with the nanosecond UV laser ablation of metals, as well as to the Gaussian laser beam profile.

With respect to the Ti, analytical results obtained for total content at sample surface and in-depth agree reasonably well with the certified value. However, there is not significant difference between the total and soluble contents determined by LA-ICPMS. Probably, the insoluble fraction of Ti is so low (as it can be deduced from the low intensity of the Ti peaks in Figs. 14 and 15) that really cannot quantitatively be distinguished. Unfortunately, only total Ti value is certified in the CRM 064-1 sample and therefore the results cannot be demonstrated. In fact, due to the great difficulty that presents the analytical differentiation between total and soluble Ti in steels by any analytical technique CRM samples with certified values for total and soluble Ti do not exist. Consequently, between the two performed tests (analysis at the sample surface and in-depth), we propose the first one (i.e., analysis at the sample surface) as a suitable alternative to the time-consuming and tedious classical method, taking into account that, in this case, the values obtained for both soluble and total Al concentration in CRM 064-1 differ significantly and agree with the certified values. In addition, this test is easier and faster than the analysis in-depth. In the case of Ti, we think that the proposed method is also acceptable for sufficiently high insoluble Ti contents, although it has not been demonstrated due to the unavailability of CRM samples with certified values for total and soluble Ti.

\section{Conclusions}

The spatial distribution (both at surface and within the sample) of $\mathrm{Al}$ and $\mathrm{Ti}$ in steel samples can be qualitatively estimated by LA-ICP-MS using single point, line scan and rastering laser sampling modes. It has been proved that the insoluble fraction of $\mathrm{Al}$ and $\mathrm{Ti}$ is heterogeneously distributed in the studied CRM steel samples. This heterogeneous distribution of the insoluble fraction may explain the high standard deviation values, as well as the poor regression coefficients obtained from the correlation of their ion intensities and certified contents. Obviously, with these samples it is not possible to establish calibration graphs for quantification. However, the use of synthetic fused beads for calibration and ${ }^{57} \mathrm{Fe}$ for internal standardization (to compensate the differences in ablation efficiency between steels and glasses) permits the bulk analysis of $\mathrm{Al}$ and $\mathrm{Ti}$ with acceptable results. Also, it allows the rapid determination of soluble and total $\mathrm{Al}$ concentration, by analysis at the sample surface, yielding results that agree reasonably well with the certified values. With regard to the determination of soluble and total Ti concentration, we believe that the proposed method is valid, too, although it could not be demonstrated due to the lack of suitable CRMs. The proposed methodology constitutes a good alternative to the difficult, laborious and time-consuming classical method, and, in addition, avoids the possible errors associated with the partial acid dissolution of the insoluble aluminium and titanium inclusions.

\section{Acknowledgements}

This work was carried out with financial support from the Comisión Interministerial de Ciencia y Tecnología (CICYT) of Spain under Project MAT2005-348.

\section{References}

[1] ASM, in: J.R. Davis, Davis \& Associates (Eds.), Specialty Handbook Carbon and Alloy Steels, ASM International, Materials Park, OH 44073-0002, USA, 1996, pp. 1-14.

[2] L. Zhang, B.G. Thomas, ISIJ Int. 43 (2003) 271.

[3] D. Günther, L. Horn, B. Hattendorf, Fresenius J. Anal. Chem. 368 (2000) 4.

[4] D. Günther, B. Hattendorf, Trends Anal. Chem. 24 (2005) 255.

[5] R.E. Russo, X. Mao, H. Liu, J. Gonzalez, S.S. Mao, Talanta 57 (2002) 425.

[6] J.S. Becker, Spectrochim. Acta, Part B 57 (2002) 1805.

[7] H. Yasuhara, T. Okano, Y. Matsumura, Analyst 117 (1992) 395.

[8] Y. Ishibashi, ISIJ Int. 37 (1997) 885.

[9] Y. Ishibashi, ISIJ Int. 42 (2002) S137.

[10] A.G. Coedo, I. Padilla, M.T. Dorado, Appl. Spectrosc. 58 (2004) 1481.

[11] D. Bleiner, A. Plotnikov, C. Vogt, K. Wetzig, D. Günther, Fresenius J. Anal. Chem. 368 (2000) 221.

[12] A. Plotnikov, C. Vogt, V. Hoffmann, C. Täschner, K. Wetzig, J. Anal. Atomic Spectrom. 12 (2001) 1290.

[13] V. Kanicky, H.R. Kuhn, D. Guenther, Anal. Bioanal. Chem. 380 (2004) 218.

[14] A.G. Coedo, T. Dorado, I. Padilla, J.C. Fariñas, J. Anal. Atomic Spectrom. 20 (2005) 612.

[15] A. Plotnikov, C. Vogt, K. Wetzig, J. Anal. Atomic Spectrom. 17 (2002) 1114.

[16] D. Bleiner, P. Lienemann, A. Ulrich, H. Vonmont, A. Wichser, J. Anal. Atomic Spectrom. 18 (2003) 1146.

[17] W. Devos, M. Senn-Luder, C. Moor, C. Salter, Fresenius J. Anal. Chem. 366 (2000) 873.

[18] D. Kang, D. Amarasiriwardena, A.H. Goodman, Anal. Bioanal. Chem. 378 (2004) 1608.

[19] A. Kindness, C.N. Sekaran, J. Feldmann, Clin. Chem. 49 (2003) 1916.

[20] J.S. Becker, M.V. Zoriy, C. Pickhardt, N. Palomero-Gallagher, K. Zilles, Anal. Chem. 77 (2005) 3208.

[21] J.S. Becker, M.V. Zoriy, M. Dehnhardt, C. Pickhardt, K. Zilles, J. Anal. Atomic Spectrom. 20 (2005) 912.

[22] A.V. Karasev, R. Inque, H. Suito, ISIJ Int. 41 (2001) 757.

[23] A.V. Izmer, M.V. Zoriy, C. Pickhardt, W. Quadakkers, V. Shemet, L. Singheiser, J.S. Becker, J. Anal. Atomic Spectrom. 20 (2005) 918. 
[24] D. Günther, A. Quadt, R. Wirz, H. Cousin, V.J. Dietrich, Mikrochim. Acta 136 (2001) 101.

[25] A.G. Coedo, I. Padilla, M.T. Dorado, Talanta 67 (2005) 136.

[26] D.B. Aeschliman, S.J. Bajic, D.P. Baldwin, R.S. Houk, J. Anal. Atomic Spectrom. 18 (2003) 872.

[27] E. Hoffmann, C. Lüdke, J. Skole, H. Stephanowitz, J. Wollbrandt, W. Becker, Spectrochim. Acta, Part B 57 (2002) 1535.
[28] M. Sanborn, K. Telmer, J. Anal. Atomic Spectrom. 18 (2003) 1231.

[29] V.N. Tokarev, J. Lopez, S. Lazare, F. Weisbuch, Appl. Phys. A 76 (2003) 385.

[30] D. Bleiner, Z. Chen, D. Auitrique, A. Bogaerts, J. Anal. Atomic Spectrom. 21 (2006) 910.

[31] O.V. Borisov, X. Mao, R.E. Russo, Spectrochim. Acta, Part B 55 (2000) 1693. 